\title{
A FRAMEWORK FOR ESTABLISHING AIR QUALITY OBJECTIVES AND TARGETS AS PART OF AN ISO 14001 PROGRAMME
}

\author{
ROBIN GARDINER \\ Gardiner Associates, PO Box 20072, Humewood, 6013
}

\section{INTRODUCTION}

Managers with the responsibility of implementing and maintaining an Environmental Management system, compliant with ISO 14001, are required to set objectives and targets for improving environmental performance. When it comes to air quality objectives, it is not unusual for managers to experience difficulties in establishing objectives that have both meaning for the organisation, and broad-based support within the management team.

Reasons for this include factors such as the uncertainty regarding what is realistic, the relative absence of legislated emission standards, and the costs associated with monitoring performance.

The purpose of this paper is to provide environmental managers with practical guidelines for setting air quality objectives and targets within industrial settings.

\section{INDUSTRIAL EMISSIONS}

Industrial air emissions vary according to their origin as well as their physical and chemical properties. Some of the characteristics of industrial air pollutants that are of importance in the setting of objectives and targets are briefly outlined in this section.

Point source emissions are those released in high concentrations at one location, for example stacks and ovens ${ }^{1}$. Non-point source emissions include planar sources, for example a number of small sources such as leaking pipes and fittings, and linear sources, such as a street with high traffic volumes. The physical distribution of emission sources influences the way in which emissions can be monitored. With point source emissions, it may be possible to install dedicated monitoring systems that, for example, optimise combustion processes through direct feedback into process settings. On the other hand, non-point sources may require the use of long-path photometry to obtain an average concentration over the site.

In cases where there is good correlation between the input materials and the resulting emissions, it is usually simpler and more accurate to monitor the consumption of input materials, e.g. organic solvents in paints and sulphur content is fuels.

The frequency of incidents or events for highly visible or odorous emissions may be an appropriate and affordable means of monitoring improvement if the emissions are mainly of nuisance value. The monitoring of complaint registers is generally discouraged due to inconsistency.

\section{SETTING OBJECTIVES AND TARGETS}

The Initial Review, conducted at the start of the planning stage of ISO 14001 implementation, provides a major source of information for the setting of objectives. Environmental aspects, including those relating to air quality, and the factors that contribute to their significance, are all identified and recorded during this process.

Factors that must be considered when selecting which of these aspects require specific objectives and targets, includes their significance, business considerations, technological options, and the views of interested parties. The rating of each aspect according to these criteria, in a similar manner to the determination of significance, can then be used to prioritise which of the aspects require specific objectives and targets. This process should result in a large reduction in the number of aspects to be addressed and a focus on those objectives and targets that will be the most productive for the environment and the organisation.

The organisation is then in a position to set objectives. The properties of good objectives and targets are described in most texts for designing projects. For objectives to be effective in driving continual improvement they should meet the requirements of SMART objectives, as described below.

Specific: The objective specifies precisely what must be achieved.

Measurable: An objective measure is essential to evaluate whether the objective has been reached. 
Achievable: The objective should be something that your organisation can accomplish.

Realistic: The objective should be practical in terms of the time frame and resources that are available.

Timebound: The objective must be tied to a specific time frame.

The written objective should include the action that will be performed, how it will be achieved, and the time period by which it will be completed.

The description for the action to be performed should include verbs that describe a behaviour, a skill, or a change in the environment ${ }^{2}$. Precise words include:

- Construct

- Locate

- Participate

- Reduce

Words to avoid include:

- Develop

- Encourage

- Enhance

Although an overall goal may be to conserve the environment, it would be difficult to measure success of such a target. These kinds of words are often used in overall mission statements for organisations, but are not effective as words in a SMART objective.

\section{OBTAINING COMMITMENT}

For the improvement programme to be successful managers with the responsibility for allocating resources to the programme must perceive the targets to be both realistic and necessary. The environmental manager's role is to establish the need for change, and provide a technical or legal justification for the targets. However, it is rare that all managers will, at least initially, find the targets achievable, and a process of obtaining buy-in is therefore necessary.

A useful framework for determining the level of participation in decision-making is the leader participation model proposed by Victor Vroom and Phillip Yeton and revised by Arthur Jago ${ }^{3}$. The model provides a set of rules to determine the amount and form of participative decisionmaking that should be encouraged in different situations. Recognising that tasks can be ${ }^{3}$ either structured of unstructured, the researchers suggested that the leader's behaviours be adjusted to the task structure.

The model suggests that the effectiveness of a decision is gauged both by its technical quality and its acceptance. According to the model, to arrive at the best decision a leader needs to analyse the situation and then choose a decisionmaking style from two autocratic styles (AI and AII), two consultative styles (CI and CII), and one group style (GII). These styles are summarised in Table $1^{4}$.

Table 1: Decision-Making Styles According to the Leader-Participation Model ${ }^{4}$

\section{Decision Style}

AI

AII

CI

CII

GII

\section{Definition}

Leader makes the decision alone

Leader asks for information from team members but makes the decision alone. Team members may or may not be informed as to what the situation is.

Leader shares the situation with each team member and asks for information and evaluation. Team members do not meet as a team, and the leader alone makes the decision.

Leader and team members meet as a team to discuss the situation, but the leader makes the decision.

Leader and team members meet as a team to discuss the situation, and the team makes the decision.

SOURCE: V.H. Vroom and P.W. Yetton. Leadership and Decision-making.

Pittsburgh: University of Pittsburgh Press, 1973 as quoted in Hellriegel et. al.

The leader's analysis is guided by eight contingency questions, which must be answered in the order they are presented in Table 2. The answer to each question guides the leader through the Vroom-Jago decision tree (see Figure 1). The leadership style chosen should lead to the highest quality decision that will be accepted by subordinates. 
Table 2: Vroom-Jago Decision Tree Questions

\begin{tabular}{|l|l|l|}
\hline & \multicolumn{1}{|c|}{ Problem Attributes } & \multicolumn{1}{c|}{ Question } \\
\hline QR & Quality requirement & How important is the technical quality of this decision? \\
\hline CR & Commitment requirement & $\begin{array}{l}\text { How important is subordinate commitment to the } \\
\text { decision? }\end{array}$ \\
\hline LI & Leader's information & $\begin{array}{l}\text { Do you have sufficient information to make a high } \\
\text { quality decision? }\end{array}$ \\
\hline PS & Problem structure & Is the problem well structured? \\
\hline CP & Commitment probability & $\begin{array}{l}\text { If you were to take the decision by yourself, is it } \\
\text { reasonably certain that your subordinate(s) would be } \\
\text { committed to the decision? }\end{array}$ \\
\hline GC & Goal congruence & $\begin{array}{l}\text { Do subordinates share the organisational goals to be } \\
\text { attained in solving the problem? }\end{array}$ \\
\hline CO & Subordinate conflict & $\begin{array}{l}\text { Is conflict among subordinates over preferred solutions } \\
\text { likely? }\end{array}$ \\
\hline SI & Subordinate information & $\begin{array}{l}\text { Do subordinates have sufficient information to make a } \\
\text { high quality decision? }\end{array}$ \\
\hline $\begin{array}{l}\text { SOURCE: V.H. Vroom and A.G. Jago. The New Leadership: Managing Participation in } \\
\text { Organisations. Englewood Cliffs, N.J.: Prentice-Hall, } 1988, \text { as quoted in Hellriegel et. al. }\end{array}$ \\
\hline
\end{tabular}

Figure 1: Vroom-Jago Decision Tree ${ }^{4}$

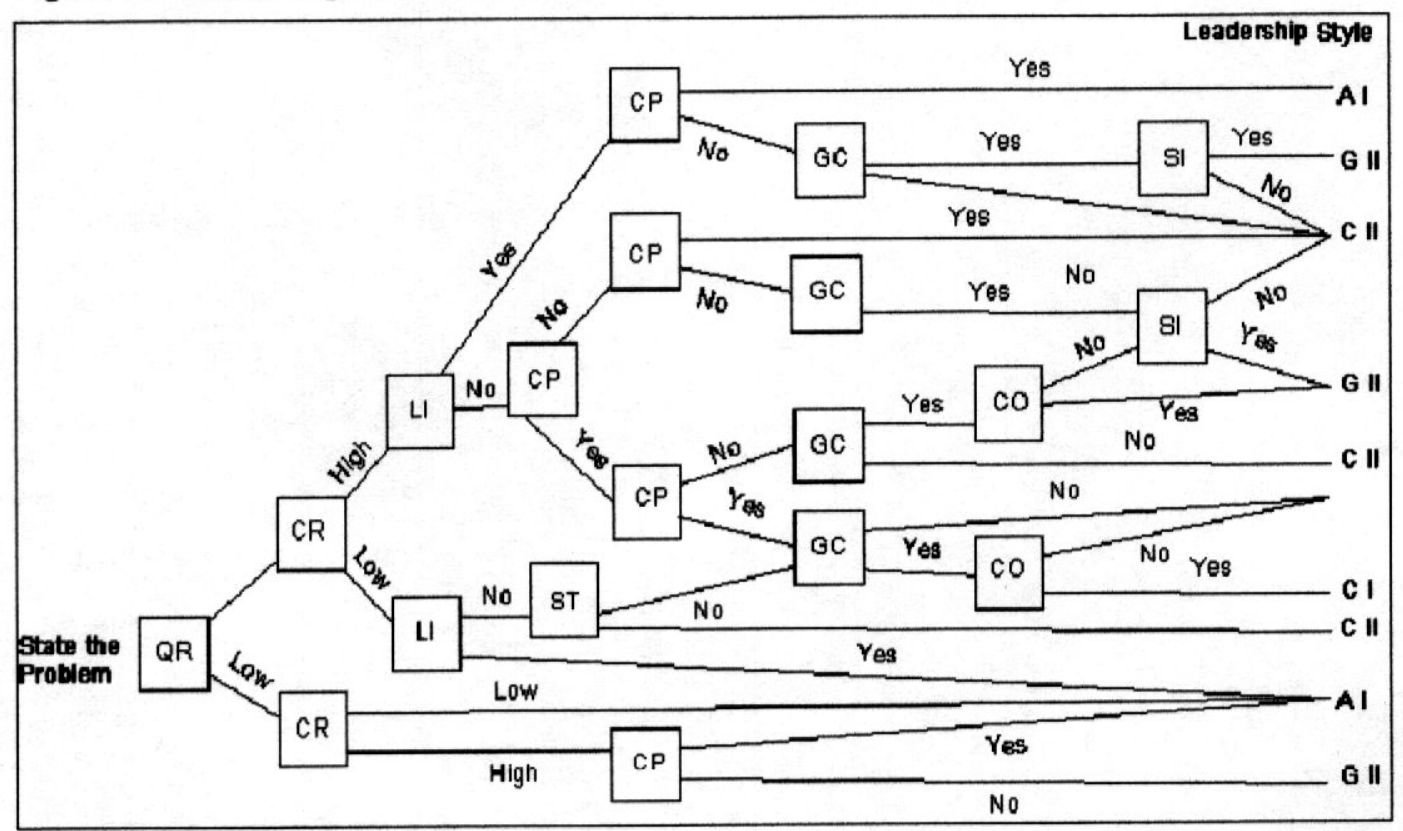

The model provides an excellent guide for determining the type and degree of participation in decision-making. While the leadership role can be assumed by the environmental manager, more weight is given to the decision, specifically in cases of autocratic decisions, if the manager to whom the team reports, assumes this role. Leaders use participation when the quality of the decision is important, when subordinates should accept the decision and they are unlikely to do so unless they are allowed to have some say in it, and when subordinates can be trusted to strive for organisational rather than individual goals.

\section{CONCLUSION}

Ensuring the commitment of managers who will have the responsibility of completing tasks in terms of the environmental management programme is key to ensuring that continual improvement targets are met. A structured approach with an appropriate level participation in the setting of objectives and targets is a major contributory factor for the successful implementation of ISO 14001. 


\section{REFERENCE LIST}

1. Baumbach G, Air Quality Control, Springer, Berlin, 1996, p 10-11.

2. Environment Canada, The Green Lane, http://www.ec.gc.ca/eco/guide/object/dig e.htm, 1998.
3. Vroom V H and Jago, A G, The New Leadership, Englewood Cliffs, N.J.: Prentice-Hall, 1988.

4. Hellriegel D, Jackson S E, Slocum J, and Staude G, Management: South African Edition, Oxford University Press, Cape Town, 2001, p 296-298. 